\title{
A Real-Time, Plate-Based BRET Assay for Detection of cGMP in Primary Cells
}

\author{
Adam L. Valkovic ${ }^{1}$, Martina Kocan ${ }^{1}$, Brad Hoare ${ }^{1}{ }^{(D}$, Sarah Marshall ${ }^{2}$ (D) Daniel J. Scott ${ }^{1,3}$ (i) \\ and Ross A. D. Bathgate $1,3, *$ (i)
}

1 Florey Institute of Neuroscience and Mental Health, The University of Melbourne, Parkville, VIC 3052, Australia; adam.valkovic@florey.edu.au (A.L.V.); martina.kocan@unimelb.edu.au (M.K.); brad.hoare@florey.edu.au (B.H.); daniel.scott@florey.edu.au (D.J.S.)

2 The Ritchie Centre, Department of Obstetrics and Gynecology, Monash University, Clayton, VIC 3168, Australia; sarah.marshall@monash.edu

3 Department of Biochemistry and Pharmacology, The University of Melbourne, Parkville, VIC 3052, Australia

* Correspondence: bathgate@florey.edu.au; Tel.: +61-3-90356735

check for

updates

Citation: Valkovic, A.L.; Kocan, M.;

Hoare, B.; Marshall, S.; Scott, D.J.; Bathgate, R.A.D. A Real-Time, Plate-Based BRET Assay for Detection of cGMP in Primary Cells. Int. J. Mol. Sci. 2022, 23, 1908. https://doi.org/10.3390/ ijms23031908

Academic Editors: Nicola Perrotti, Bonnie Blazer Yost and Marcin Majka

Received: 15 December 2021

Accepted: 4 February 2022

Published: 8 February 2022

Publisher's Note: MDPI stays neutral with regard to jurisdictional claims in published maps and institutional affiliations.

Copyright: (C) 2022 by the authors. Licensee MDPI, Basel, Switzerland. This article is an open access article distributed under the terms and conditions of the Creative Commons Attribution (CC BY) license (https:// creativecommons.org/licenses/by/ $4.0 /)$.

\begin{abstract}
Cyclic guanosine monophosphate (cGMP) is a second messenger involved in the regulation of numerous physiological processes. The modulation of cGMP is important in many diseases, but reliably assaying cGMP in live cells in a plate-based format with temporal resolution is challenging. The Förster/fluorescence resonance energy transfer (FRET)-based biosensor cGES-DE5 has a high temporal resolution and high selectivity for cGMP over cAMP, so we converted it to use bioluminescence resonance energy transfer (BRET), which is more compatible with plate-based assays. This BRET variant, called CYGYEL (cyclic GMP sensor using YFP-PDE5-Rluc8), was cloned into a lentiviral vector for use across different mammalian cell types. CYGYEL was characterised in HEK293T cells using the nitric oxide donor diethylamine NONOate (DEA), where it was shown to be dynamic, reversible, and able to detect cGMP with or without the use of phosphodiesterase inhibitors. In human primary vascular endothelial and smooth muscle cells, CYGYEL successfully detected cGMP mediated through either soluble or particulate guanylate cyclase using DEA or C-type natriuretic peptide, respectively. Notably, CYGYEL detected differences in kinetics and strength of signal both between ligands and between cell types. CYGYEL remained selective for cGMP over cAMP, but this selectivity was reduced compared to cGES-DE5. CYGYEL streamlines the process of cGMP detection in plate-based assays and can be used to detect cGMP activity across a range of cell types.
\end{abstract}

Keywords: cGMP; BRET; biosensor; cell signalling

\section{Introduction}

Cyclic guanosine monophosphate (cGMP) is a second messenger involved in the regulation of many physiological processes including cardiovascular homeostasis, smooth muscle tone, blood pressure, platelet aggregation, memory, learning, and sensory transduction [1-3]. cGMP is synthesised from guanosine triphosphate (GTP) by two forms of guanylate cyclase (GC): soluble GCs (sGCs), which are cytosolic enzymes activated by nitric oxide (NO) and carbon monoxide [4]; and particulate GCs (pGCs), which are membrane receptors activated by natriuretic peptides and some intestinal peptides [5]. cGMP signals via protein kinase $\mathrm{G}$ (PKG) and cyclic nucleotide-gated ion channels, and also modulates the activity of some phosphodiesterases (PDEs) [6]. cGMP is degraded by PDE-mediated hydrolysis [6].

Modulation of cGMP activity has therapeutic value for several disorders. For example, NO donors such as glyceryl trinitrate are used to treat angina [7], the sGC stimulator riociguat is used for treatment of pulmonary arterial hypertension and chronic thromboembolic pulmonary hypertension [8], PDE5 inhibitors such as sildenafil and vardenafil are used to treat erectile dysfunction [9], and agonists for GC-C (a type of pGC) such 
as linaclotide and plecanatide are used to treat irritable bowel syndrome with constipation [10]. Natriuretic peptides are also under investigation for the treatment of cardiovascular disorders such as heart failure [11], and drug discovery targeting cGMP signalling cascades is under continued investigation for the treatment of a variety of other disorders and diseases [12-16].

cGMP is usually measured in populations of cells in a plate-based format using traditional end point signalling assays that involve the detection of cGMP in cell lysates. However, although such assays may be sensitive, they are laborious, as cells must be lysed at individual time points. Furthermore, end point cGMP assays usually require the addition of PDE inhibitors to stop the breakdown of cGMP, leading to the accumulation and measurement of total cGMP, which can produce a type of "observational bias", whereby the dynamics of cGMP are not easily detected, leading to an incomplete or misleading idea of the signalling patterns induced by different ligands [17]. Conversely, assays that can detect cGMP activity in real time will help remove the confounding effects of observational bias and will also allow more efficient examination of the kinetic aspects of signalling.

Genetically encoded biosensors based on Förster/fluorescence resonance energy transfer (FRET) are sometimes used to image cGMP activity in real time in single cells [18-20], where FRET refers to the transfer of energy from an excited donor fluorophore to an appropriate acceptor fluorophore when they are in close proximity [21]. These FRET-based biosensors for cGMP consist of a "sensor" domain that binds cGMP, which is sandwiched by an appropriate FRET donor/acceptor fluorophore pair such as cyan fluorescent protein (CFP)/yellow fluorescent protein (YFP). When cGMP binds to the sensor, the FRET pair moves either closer together or farther apart, producing a change in FRET that can be monitored in real time. However, although FRET-based biosensors are valuable for cellular microscopy and imaging of single cells with high spatial and temporal resolution, they are less suited for the detection of activity from populations of cells in plate-based assays, due to the higher background noise and photobleaching of the donor caused by laser excitation [22]. In contrast, bioluminescence resonance energy transfer (BRET), which uses a luciferase rather than a fluorescent protein as the donor, is a more sensitive technique for plate-based assays, as luciferases do not require laser excitation, but rather emit light after oxidation of a substrate molecule. As a result, BRET assays do not induce photobleaching of the donor, and show a lower background noise and a higher signal-to-noise ratio than FRET assays [22].

A BRET-based assay for cGMP activity would allow for high sensitivity, real-time detection of cGMP activity in live cells in a plate-based assay, which is more suited to ligand screening and pharmacological characterisation than imaging of single cells. Therefore, we report here the conversion of the cGES-DE5 FRET-based cGMP biosensor [19] to a BRET-based biosensor (cyclic GMP sensor using YFP-PDE5-Rluc8; CYGYEL), cloning of the novel biosensor into a lentiviral vector for stable expression in mammalian cells, validation and characterisation of the biosensor in live cells in a real-time multi-well plate-based format, and investigation of the applicability of the sensor for the detection of sGC- and pGC-mediated cGMP activity in human primary vascular cells.

\section{Results}

2.1. Design of a BRET-Based Biosensor for cGMP Activity and Generation of a Stably Expressing HEK293T Cell Line

Several FRET-based biosensors have been engineered and used to detect cGMP in single cells, including CGY [20], cygnet [18], and cGi [23], which use truncated forms of PKG as the "sensor" element, and cGES-DE5, which uses the cGMP-binding domain from human PDE5A as the "sensor" [19]. cGES-DE5 was chosen as the basis to generate a BRET-based biosensor due to its superior temporal resolution and high selectivity for cGMP over cAMP (approximately 420-fold), compared to other FRET-based sensors [19]. To convert cGES-DE5 to BRET, the sequence for the ECFP donor was replaced with the sequence for the luciferase Rluc8. Additionally, the sequence for EYFP was replaced with 
the sequence for Venus, due to its increased brightness (Figure 1A). The resulting sensor was named CYGYEL (cyclic GMP sensor using YFP-PDE5-Rluc8). Upon binding of cGMP to the cGMP-binding domain, the sensor was expected to respond by decreasing the distance between donor and acceptor, leading to an increase in BRET ratio.
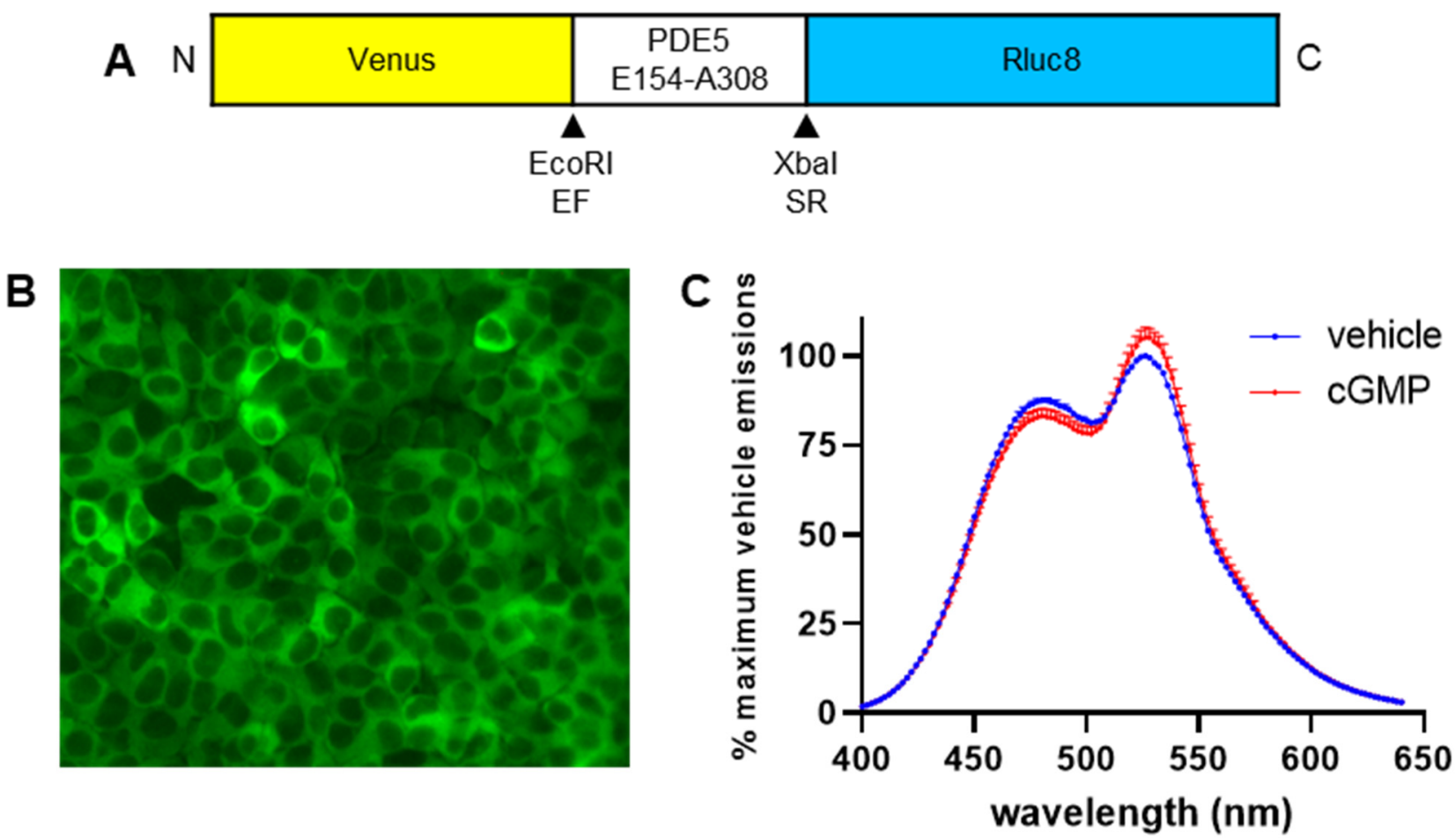

Figure 1. Design and expression of cyclic GMP sensor using YFP-PDE5-Rluc8 (CYGYEL), a bioluminescence resonance energy transfer (BRET)-based biosensor for cyclic guanosine monophosphate (cGMP) activity. (A) The isolated cGMP-binding domain from human phosphodiesterase (PDE) 5 is sandwiched between Venus and Rluc8. (B) HEK293T cells were transduced with CYGYEL lentivirus (HEK-CYGYEL cells) and sorted by fluorescence-activated cell sorting. A "high-expressing" population was imaged using a fluorescence microscope (20× magnification). (C) A spectral scan was generated after stimulating lysates of HEK-CYGYEL cells with cGMP $(100 \mu M)$. Spectral scan data are the mean and standard error of the mean (SEM) of data from three independent assays.

As the biosensor was intended for use in human primary cells that are difficult to transfect, it was cloned into a lentiviral vector under the control of the constitutive human Ef1 $\alpha$ promoter to enable viral delivery of the sensor. Lentivirus was produced and used to transduce HEK293T cells, which were sorted by FACS into populations that expressed low, medium, or high levels of the biosensor (Figure S2). To visualise the expression of CYGYEL in these cells, Venus emissions were detected from the "high" expressing cells using a GFP filter on a fluorescence microscope (Figure 1B), demonstrating that CYGYEL shows diffuse cytoplasmic expression, suggesting that it is likely to be able to detect cGMP throughout the cell in live cell assays. Furthermore, to determine whether CYGYEL responds to cGMP with an increase in BRET, the population of cells expressing "high" levels of CYGYEL were lysed, and spectral scans were generated from cell lysates in the absence or presence of cGMP (Figure 1C). As with cGES-DE5 [19], CYGYEL showed basal activation, but the relative intensity of emissions from Rluc8 relative to Venus changed upon the addition of cGMP $(100 \mu \mathrm{M})$.

\subsection{Characterisation of Real-Time cGMP Activity in Live Cells}

CYGYEL was next characterised as a real-time signalling assay in live HEK293T cells. HEK-CYGYEL cells were stimulated for 90 min with the NO donor diethylamine NONOate 
(DEA), which releases NO via a pH-dependent mechanism [24], leading to the synthesis of cGMP via sGC (Figure 2). In the absence of PDE inhibitors, there were steep increases in the BRET ratio for at least 25 min following the treatment with DEA, representative of increases in CGMP (Figure 2A). The response then either remained relatively steady before showing a slow decline (DEA $100 \mu \mathrm{M}$ ) or declined for the duration of the time course (DEA $10 \mu \mathrm{M}$ ). As expected, preincubation with the cGMP-specific PDE5 inhibitor vardenafil (100 nM; approximately $10 \mathrm{~min}$ ) led to more sustained increases in BRET ratio for both concentrations of DEA as well as higher maximum responses that peaked at approximately $40 \mathrm{~min}$, which was much later than in the absence of vardenafil (Figure 2B), suggesting that the more transient responses seen without vardenafil were at least partly due to the PDE5-mediated degradation of cGMP. Similarly, the addition of vardenafil after an extended incubation with DEA (40.5 min) led to further increases in cGMP for both tested concentrations of DEA, although the effect was more pronounced for $100 \mu \mathrm{M}$ DEA and was sustained for the duration of the time course, in contrast to $10 \mu \mathrm{M}$, which started to decline after a brief increase (Figure 2C). These results demonstrate that the biosensor is dynamic and able to detect robust increases and decreases in cGMP over an extended period of time (at least $90 \mathrm{~min}$ ). To demonstrate the full dynamic range of the biosensor, cells were stimulated with DEA after pretreatment (approximately $10 \mathrm{~min}$ ) with the nonselective PDE inhibitor IBMX $(500 \mu \mathrm{M})$ (Figure 2D). In comparison to the response in the presence of vardenafil, the response for $10 \mu \mathrm{M}$ DEA in the presence of IBMX was more sustained.
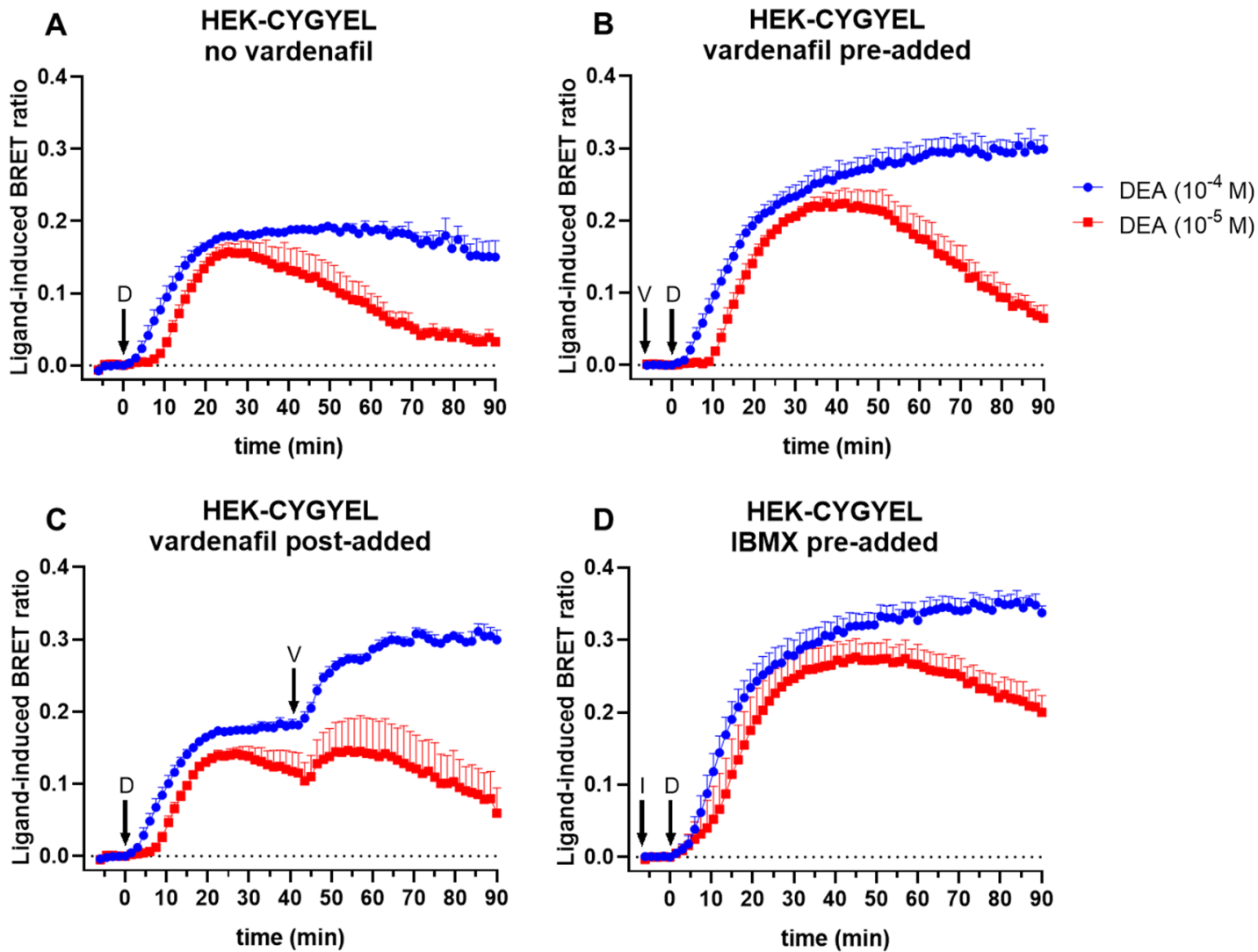

Figure 2. Characterisation of the CYGYEL BRET-based biosensor for cGMP activity in live cells. Intracellular cGMP was detected in real time after stimulation of HEK-CYGYEL cells with the nitric oxide (NO) donor DEA. Cells were stimulated with diethylamine NONOate (DEA) (D; 10 or $100 \mu \mathrm{M})$ for $90 \mathrm{~min}$ (min) either (A) without any PDE inhibitors, (B) with the cGMP-specific PDE5 inhibitor vardenafil (V; $100 \mathrm{nM}$ ) pre-added (approximately $10 \mathrm{~min}$ ), (C) with vardenafil added after $40.5 \mathrm{~min}$, or (D) with the nonselective PDE inhibitor 3-isobutyl-1-methylxanthine (IBMX) (I; $500 \mu \mathrm{M})$ pre-added (approximately $10 \mathrm{~min}$ ). Time of ligand or vehicle addition is represented by arrows. Data are mean and SEM of three independent experiments. 
To further demonstrate reversibility of the sensor, and blocking of the cGMP response, cells were stimulated with DEA in the absence or presence of the SGC inhibitor ODQ $(100 \mu \mathrm{M})$ (Figure 3). The blockade of sGC with ODQ for approximately $10 \mathrm{~min}$ before addition of DEA either abolished the DEA response (10 $\mu \mathrm{M}$ DEA) or almost abolished it while also delaying the peak response until about 40 min rather than about $25 \mathrm{~min}(100 \mu \mathrm{M}$ DEA) (Figure 3B). Furthermore, the addition of ODQ after a 20.5-min stimulation with DEA led to near-immediate decreases in the cGMP response (Figure $3 \mathrm{C}$ ), again demonstrating that CYGYEL is specific for CGMP, dynamic, and reversible.
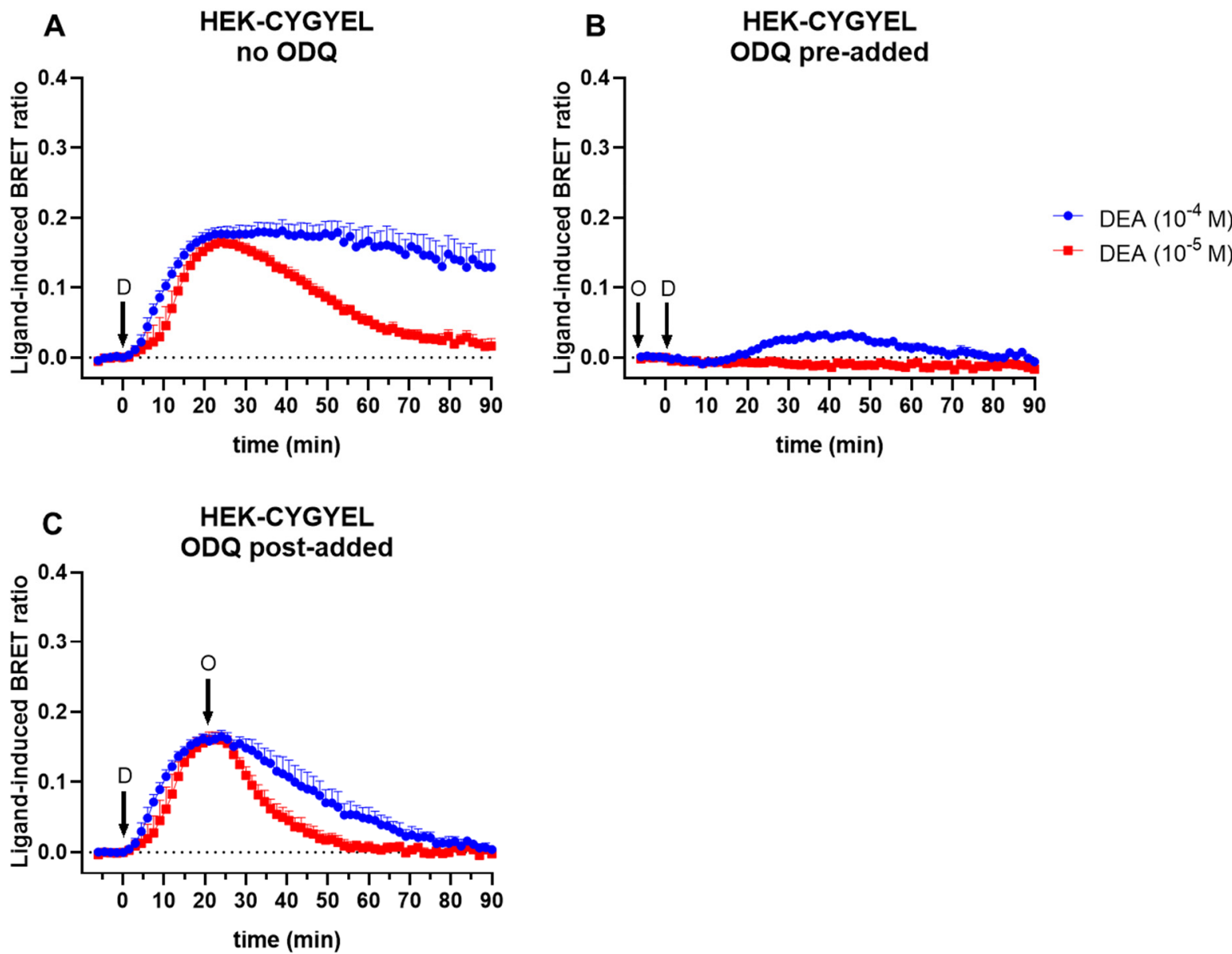

Figure 3. Blocking and reversing the cGMP sensor signal in HEK-CYGYEL cells. Intracellular cGMP was detected in real time after stimulation of HEK293T cells stably expressing CYGYEL with the NO donor DEA (D; 10 or $100 \mu \mathrm{M})$ in the absence or presence of the sGC inhibitor ODQ (O; $100 \mu \mathrm{M}$ ). (A) Cells were stimulated with DEA without ODQ. (B) Cells were stimulated with DEA after preincubation (approximately $10 \mathrm{~min}$ ) with ODQ. (C) Cells were stimulated with DEA for $20.5 \mathrm{~min}$ before addition of ODQ. Time of ligand or vehicle addition is represented by arrows. Data are mean and SEM of three independent experiments.

\subsection{Selectivity of CYGYEL for cGMP over cAMP}

One concern for the use of genetically encoded biosensors for cGMP activity is that cAMP can still potentially bind to and "activate" the sensor, albeit with a lower potency than that of cGMP. This crosstalk might pose a problem when detecting signalling from ligands that increase the levels of both cGMP and cAMP, or when the basal concentration of cAMP inside the cell is high, leading to a high background activation of the sensor. The FRET-based biosensor cGES-DE5 was activated by cGMP with a potency of $\sim 1.5 \mu \mathrm{M}$ and by cAMP with a potency of $\sim 630 \mu \mathrm{M}$, which corresponds to an approximately 420 -fold higher selectivity for cGMP than cAMP [19]. To compare these results to our BRET variant, 
HEK-CYGYEL lysates were directly stimulated with a range of concentrations of cGMP or cAMP (Figure 4A-C). cGMP (Figure 4A) and cAMP (Figure 4B) both increased the BRET ratio in a concentration-dependent manner, however it was clear that higher concentrations of cAMP were required to activate the sensor relative to CGMP, and that CAMP also induced a slower activation of the sensor than CGMP, particularly at the higher concentrations of ligand $(100 \mu \mathrm{M}$ and $1 \mathrm{mM}$ cAMP). Concentration-response curves were generated by taking the area under the curve, which revealed that cGMP activated CYGYEL with a potency of $1.32 \pm 0.43 \mu \mathrm{M}$, whereas cAMP activated CYGYEL with a potency of $42.15 \pm 15.44 \mu \mathrm{M}$ (Figure 4C; Table 1). Thus, cGMP showed an approximately 32-fold higher selectivity for activation of CYGYEL relative to CAMP, compared with the higher selectivity seen for cGES-DE5.

Table 1. Potency of cGMP for activation of CYGYEL. HEK293T cells stably expressing CYGYEL were lysed and stimulated with a range of concentrations of cGMP or cAMP. Potencies were calculated by taking the area under the curve from the time-course data. Selectivity was determined by dividing the $\mathrm{EC}_{50}$ for $\mathrm{CAMP}$ by the $\mathrm{EC}_{50}$ for CGMP. Data are the mean and SEM of four independent experiments. ${ }^{*} p<0.05$ compared to cGMP in an unpaired $t$-test.

\begin{tabular}{cccc}
\hline & cGMP & cAMP & cAMP/cGMP \\
\hline EC $_{\mathbf{5 0}}(\mu \mathrm{M})$ & $1.32 \pm 0.43$ & $42.15 \pm 15.44$ & 32 \\
\hline pEC $_{\mathbf{5 0}}$ & $5.88 \pm 0.14$ & $4.38 \pm 0.16^{*}$ & \\
\hline
\end{tabular}

However, although these results reflect the biochemistry that occurs in cell lysates, they do not necessarily reflect what may occur in pharmacological assays using live cells, as cell lysate assays do not reflect, for example, the localisation of second messengers into microdomains or localised PDE activity. Thus, to understand whether cAMP activates CYGYEL in live cell assays, we compared cAMP-mediated activation of CYGYEL to cAMP-mediated activation of the cAMP sensor CAMYEL [25] in live cells by stimulating HEK-CYGYEL and HEK-CAMYEL cells with the adenylate cyclase activator forskolin (Figure 4D-F). Time courses showed sustained increases in BRET ratio for the duration of a 60 min stimulation for both CAMYEL (Figure 4D) and CYGYEL (Figure 4E). Concentrationresponse curves revealed that the forskolin response was detected with a potency of $0.62 \pm 0.06 \mu \mathrm{M}$ in CAMYEL cells and 100.5 $\pm 11.8 \mu \mathrm{M}$ in CYGYEL cells (Figure 4F; Table 2). Thus, in live HEK293T cells, cAMP activated CAMYEL with a 160-fold higher potency than it activated CYGYEL.

Table 2. Forskolin-mediated cAMP activation of the CAMYEL and CYGYEL biosensors expressed in HEK293T cells. HEK293T cells stably expressed with either the CAMYEL cAMP sensor or CYGYEL were stimulated with a range of concentrations of forskolin. Concentration-response curves were generated by taking the area under the curve from the time-course data, normalised to maximum forskolin response in order to compare the potencies $\left(\mathrm{EC}_{50}\right.$ and $\left.\mathrm{pEC}_{50}\right)$ of forskolin for downstream activation of each biosensor. Data are mean and SEM of three independent experiments. ${ }^{*} p<0.05$ compared to HEK-CAMYEL in an unpaired $t$-test.

\begin{tabular}{ccc}
\hline Forskolin & HEK-CAMYEL & HEK-CYGYEL \\
\hline EC $_{\mathbf{5 0}}(\boldsymbol{\mu M})$ & $0.62 \pm 0.06$ & $100.5 \pm 11.8$ \\
\hline pEC $_{50}$ & $6.21 \pm 0.04$ & $3.99 \pm 0.05^{*}$ \\
\hline
\end{tabular}

\subsection{Detection of cGMP in Human Primary Vascular Cells}

We next aimed to determine whether CYGYEL can effectively detect cGMP activity in human primary cells. Given that CGMP is a key signalling pathway for the regulation of cardiovascular physiology, we transduced human primary vascular cells, specifically, human umbilical vein endothelial cells (HUVECs) and human umbilical vein smooth 
muscle cells (HUVSMCs), with CYGYEL. Fluorescence-activated cell sorting was then used to remove cells that were not successfully transduced (Figures S3 and S4).
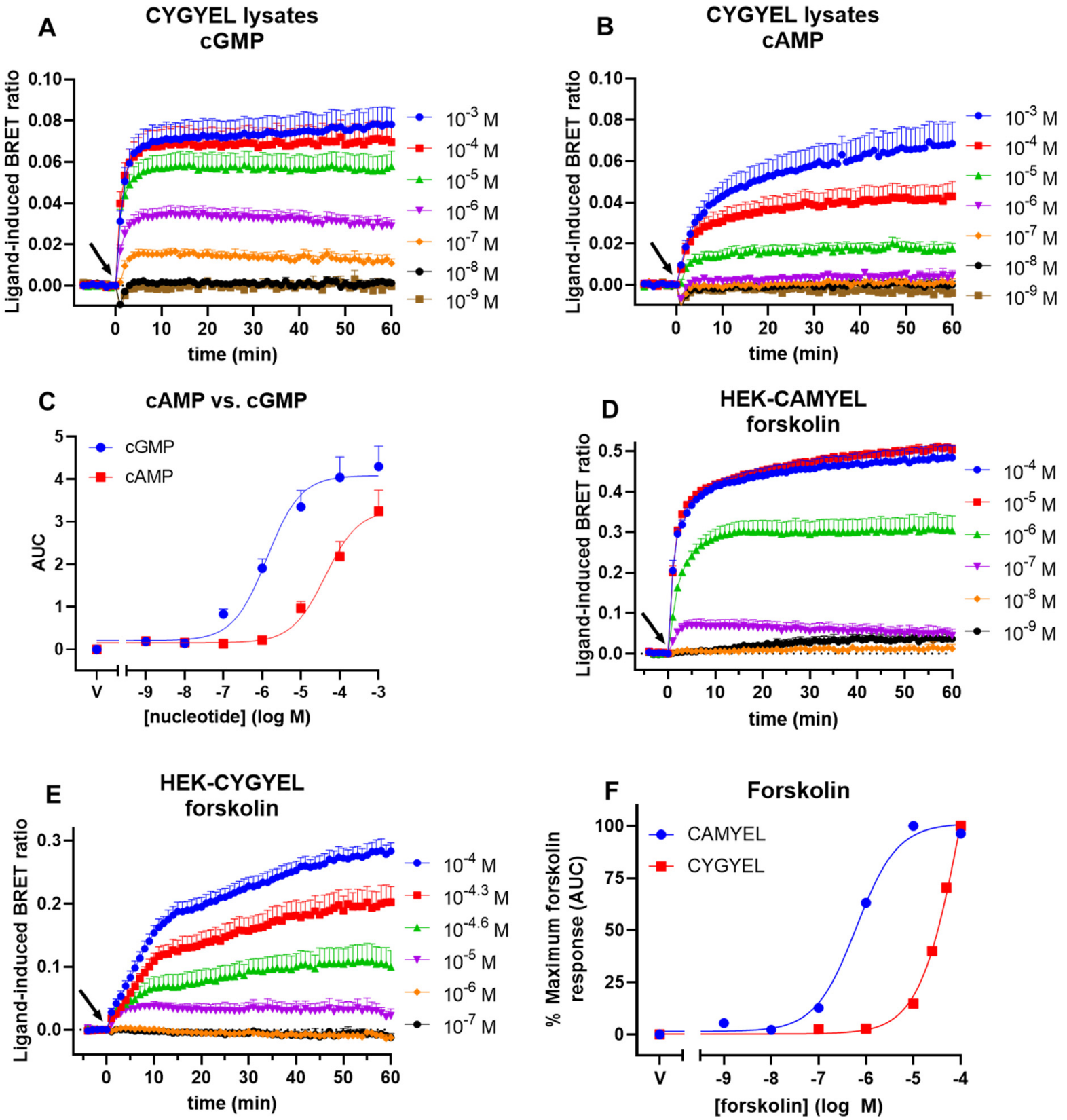

Figure 4. Activation of the CYGYEL cGMP sensor by cGMP and cAMP. Lysates from HEK293T cells stably expressing CYGYEL were stimulated with a range of concentrations of (A) cGMP or (B) cAMP for $60 \mathrm{~min}$. (C) Concentration-response curves were generated by taking the area under the curve (AUC) from the time-course data. Live HEK293T cells stably expressing (D) the cAMP sensor using YFP-Epac-Rluc (CAMYEL) BRET-based cAMP biosensor or (E) CYGYEL were stimulated with a range of concentrations of forskolin for $60 \mathrm{~min}$. (F) Concentration-response curves were generated by taking the area under the curve from the time-course data, normalised as a percentage of maximum forskolin response. Time of vehicle or ligand addition is represented by an arrow. Data are the mean and SEM of three or four independent experiments.

To detect sGC-mediated cGMP activity, HUVSMC-CYGYEL and HUVEC-RXFP1CYGYEL cells were stimulated with the NO donor DEA, in the absence of any PDE inhibitors (Figure 5). Time courses for HUVSMCs showed robust, concentration-dependent 
increase in cGMP activity (Figure 5A), which were transient at submaximal concentrations of DEA. In contrast, concentration-dependent data were unable to be generated for HUVECs, as responses were difficult to detect (Figure 5B). Concentration-response curves were generated for HUVSMCs, demonstrating a potency $\left(\mathrm{EC}_{50}\right)$ in the micromolar range (Figure 5C, Table 3).
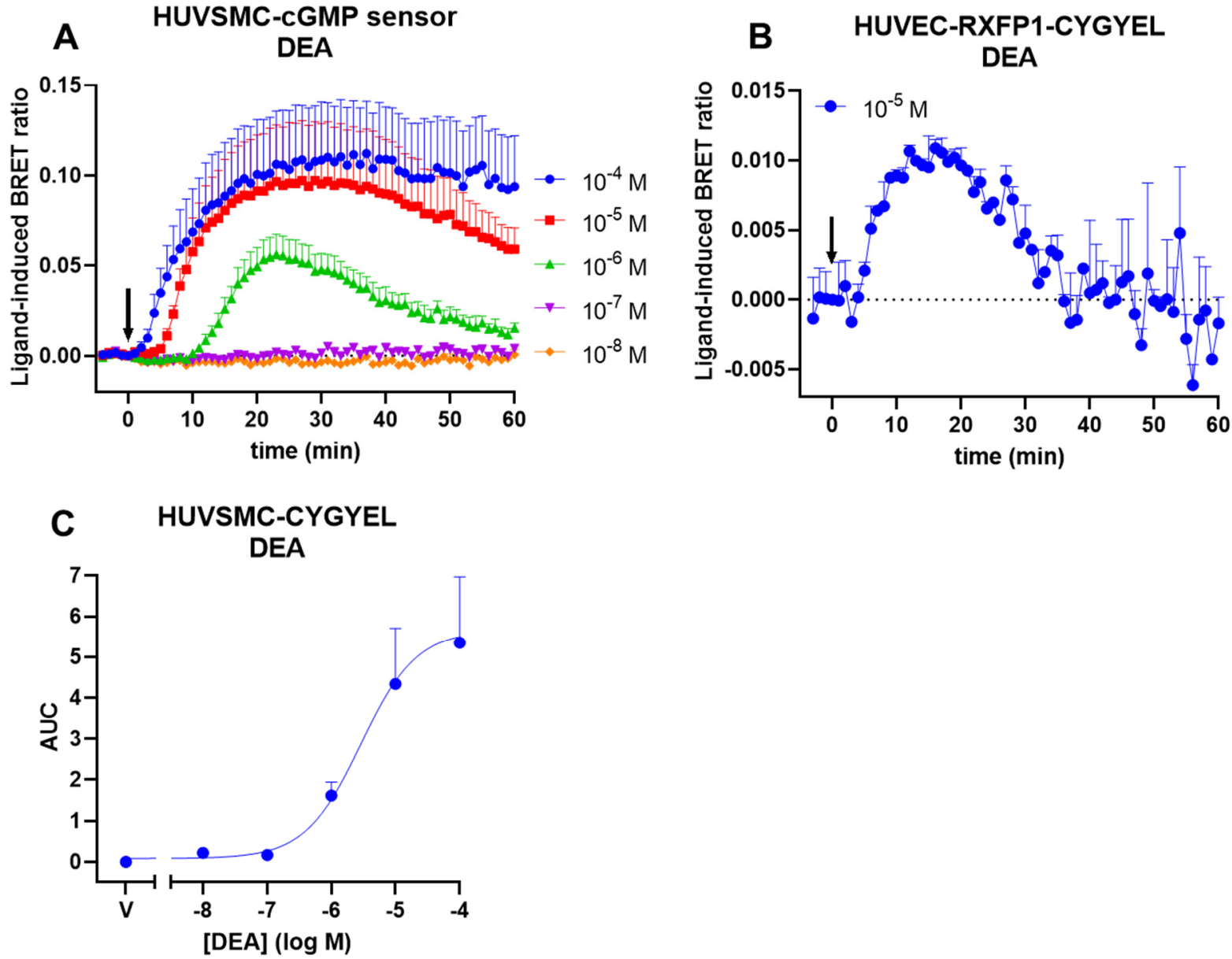

Figure 5. DEA-induced cGMP activity in human umbilical vein smooth muscle cells (HUVSMCs) and human umbilical vein endothelial cells (HUVECs). HUVSMCs and HUVECs stably expressing CYGYEL were stimulated with vehicle or the nitric oxide donor DEA for $60 \mathrm{~min}$. Time courses were generated for (A) HUVSMCs and (B) HUVECs. (C) Concentration-responses curves were generated by taking the area under the curve (AUC) from the time-course data. Time of vehicle or DEA addition is represented by an arrow. Data are the mean and SEM for two (panel B) or four independent experiments.

Table 3. Potency of DEA and CNP for cGMP activity in HUVSMCs and HUVECs. HUVSMCs and HUVECs stably expressing CYGYEL were stimulated with the NO donor DEA or the GC-B agonist $\mathrm{CNP}$ for $60 \mathrm{~min}$. The potencies $\left(\mathrm{EC}_{50}\right.$ and $\left.\mathrm{pEC}_{50}\right)$ were determined by taking the area under the curve (AUC) from the time-course data. Data are the mean and SEM for three or four independent experiments.

\begin{tabular}{ccccc}
\hline & \multicolumn{2}{c}{ DEA } & \multicolumn{2}{c}{ CNP } \\
\hline & HUVSMC & HUVEC & HUVSMC & HUVEC \\
\hline EC $_{\mathbf{5 0}}$ & $2.88 \pm 2.34 \mu \mathrm{M}$ & - & $87.01 \pm 20.39 \mathrm{nM}$ & $88.97 \pm 29.41 \mathrm{nM}$ \\
\hline $\mathrm{pEC}_{\mathbf{5 0}}$ & $5.54 \pm 0.35$ & - & $7.06 \pm 0.10$ & $7.05 \pm 0.14$ \\
\hline
\end{tabular}


In addition to sGC-mediated cGMP production, CYGYEL was tested for its ability to detect pGC-mediated cGMP activity in human vascular cells (Figure 6). HUVSMCs and HUVECs were stimulated with a range of concentrations of C-type natriuretic peptide (CNP), which activates the GC-B form of pGC, for $60 \mathrm{~min}$. Time courses generated for HUVSMCs (Figure 6A) and HUVECs (Figure 6B) showed concentration-dependent increases in cGMP activity after CNP stimulation, which reached maximum activity at $1-5 \mu \mathrm{M}$ for both cell types. However, whereas the cGMP responses in HUVSMCs were relatively sustained for the duration of the time course, the cGMP responses in HUVECs peaked at about $10 \mathrm{~min}$ before showing a slow decline that started to stabilise by the end of the time course. Concentration-response curves demonstrated that CNP had a near-identical potency for cGMP increases in both cell types (Figure 6C, Table 3). Additionally, the shapes of the time courses were different for CNP compared with DEA, with CNP responses being more sustained, consistent with the different mechanisms of action of these two different types of drugs.
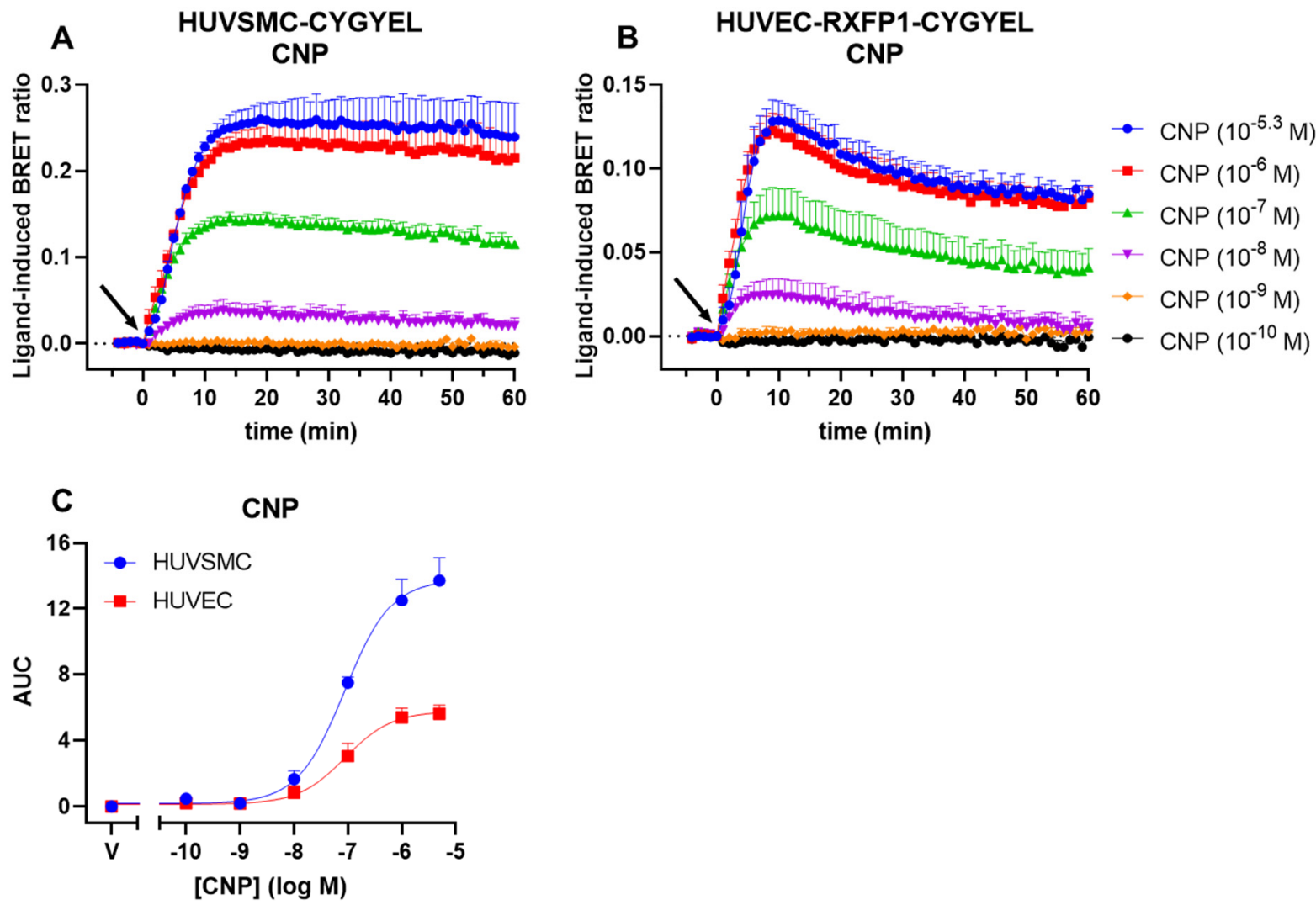

Figure 6. CNP-induced cGMP activity in HUVSMCs and HUVECs. HUVSMCs and HUVECs stably expressing CYGYEL were stimulated with vehicle or C-type natriuretic peptide (CNP) for $60 \mathrm{~min}$. Time courses were generated for (A) HUVSMCs and (B) HUVECs. (C) Concentration-response curves were generated by taking the AUC from the time-course data. Time of vehicle or CNP addition is represented by an arrow. Data are the mean and SEM for three independent experiments.

\section{Discussion}

Traditional end point signalling assays for cGMP do not easily measure the temporal aspects of signalling as they require lysing cells at individual time points and usually employ PDE inhibitors to allow the accumulation of cGMP to detectable levels. The ability of BRET-based biosensors to detect signalling in real time in plate-based cellular assays prompted us to develop a BRET-based biosensor for cGMP activity. The FRETbased biosensor cGES-DE5 was converted to BRET due to its high selectivity for cGMP over cAMP and high temporal resolution compared with other available biosensors [19]. 
This was accomplished by substituting the region coding for ECFP with Rluc8, as well as swapping the region coding for EYFP to Venus. The resulting biosensor, which was named CYGYEL, was cloned into a lentiviral vector and subsequently tested across several cell types including human primary vascular cells, where it successfully detected real-time changes in cGMP activity, and in some cases showed differences in temporal patterns between ligands and cell types.

First, HEK293T cells were transduced and sorted by FACS for basic characterisation of the sensor. The imaging of HEK-CYGYEL cells using a fluorescence microscope demonstrated that CYGYEL was expressed throughout the cytoplasm, suggesting that the detection of cGMP throughout the cell would be possible. Real-time assays in these cells showed that CYGYEL detects robust increases and decreases in sGC-mediated cGMP activity for extended periods of time (at least $90 \mathrm{~min}$ ) after stimulation with a NO donor. The assay was sensitive enough to detect cGMP activity in the absence of any PDE inhibitors, but the addition of the cGMP-specific PDE5 inhibitor vardenafil or the nonspecific PDE inhibitor IBMX did increase the BRET ratio and prolong the response. Furthermore, preincubation with the SGC inhibitor ODQ diminished or abolished the increases in BRET ratio, depending on the DEA concentration, further confirming the assay was specific for cGMP activity.

Following this, we demonstrated that CYGYEL can detect cGMP activity mediated through both sGC and pGC in human primary vascular cells, specifically HUVECs and HUVSMCs. Interestingly, we observed differences in cGMP signalling both between cell types and between ligands. Both cell types showed robust, concentration-dependent responses to CNP, but cGMP activity was more sustained in HUVSMCs than in HUVECs. Notably, however, the potency of CNP was almost identical between cell types. In contrast, DEA responses were weak and difficult to detect in HUVECs, whereas there were robust, concentration-dependent DEA-mediated cGMP increases in HUVSMCs, which were also substantially less potent than the CNP responses. Furthermore, CNP showed faster increase in cGMP compared with DEA, consistent with the role of CNP as a membrane receptor agonist, compared with DEA, which is a NO donor. Additionally, the weak responses to DEA observed in HUVECs, compared with strong responses to CNP observed in the same cell type, are consistent with findings from other studies showing that natriuretic peptides induced stronger cGMP responses in HUVECs compared with NO donors [26,27]. Finally, as robust cGMP activity was detected in both types of vascular cells tested, it is expected that the lentiviral vector, which uses a constitutive human promoter, will also aid in the detection of cGMP across a variety of other cell types.

One potential concern for the use of genetically encoded cGMP sensors is that cAMP can also bind to cGMP-binding domains, including the binding domain from PDE5, albeit with a lower affinity than cGMP. As noted, the low crosstalk from cAMP observed for cGES-DE5 was one of the primary reasons this sensor was chosen as the basis to generate CYGYEL. In lysates from TsA201 cells, cGES-DE5 was activated by cGMP with a potency of about $1.5 \mu \mathrm{M}$ and by cAMP with a potency of about $630 \mu \mathrm{M}$ [19]. Here, we demonstrated that CYGYEL was activated by cGMP with a potency $\left(\mathrm{EC}_{50}\right)$ of about $1.3 \mu \mathrm{M}$ and by cAMP with a potency of about $42 \mu \mathrm{M}-$ a selectivity of about 32-fold. Thus, although the $\mathrm{EC}_{50}$ of $\mathrm{cGMP}$ is comparable between the two variants of the biosensor, the $\mathrm{EC}_{50}$ of cAMP is considerably lower for the activation of CYGYEL than cGES-DE5. As noted, however, results from such biochemical assays in cell lysates will not always reflect what occurs in live cells due to a variety of factors such as localised cyclic nucleotide and PDE activity. Therefore, we also tested the ability of cAMP to activate CYGYEL in live cell assays by stimulating HEK-CYGYEL cells with the adenylate cyclase activator forskolin and compared these results to those observed for the same assay conducted in HEK-CAMYEL cells. These findings showed that in contrast to the activation of CAMYEL, relatively high concentrations of forskolin were required to induce a robust activation of CYGYEL, and that there was a 160-fold difference in forskolin potencies between the activation of the two sensors. However, it should also be noted that cAMP-mediated activation of CYGYEL may 
depend on the cell type being tested due to differential expression of adenylate cyclases and PDEs, for example, so users of this biosensor should carefully consider this. On the other hand, it is also important to note that for many applications of CYGYEL, such as screening of NO donors and pGC agonists as conducted here, the crosstalk from cAMP may not be an important factor. Examples of situations where crosstalk may be important include situations when using a ligand induces the activation of both cGMP and cAMP, or when using cell types that have high background levels of cAMP. Furthermore, other characteristics of a sensor, such as its temporal resolution, are also equally important to consider in the choice of a biosensor. As noted, for example, the superior temporal resolution of cGES-DE5 reported by Nikolaev et al. [19], compared with other available FRET-based biosensors, was the other key reason that we chose cGES-DE5 as the basis for our BRET variant.

We also note the development of another BRET-based biosensor for cGMP, known as GFP'2-GAFa-Rluc [28]. This biosensor is based on the BRET ${ }^{2}$ methodology [29], using the combination of Rluc, GFP ${ }^{2}$, and DeepBlueC as the substrate, compared with CYGYEL which is based on BRET ${ }^{1}$, using the combination of Rluc8, Venus, and coelenterazine $h$. GFP $^{2}$-GAFa-Rluc uses a longer segment of PDE5A than CYGYEL, which is sandwiched between the Rluc donor and GFP ${ }^{2}$ acceptor. In lysates from transfected cells, cGMP had a surprisingly low $\mathrm{EC}_{50}$ of approximately $30 \mathrm{nM}$ for the activation of GFP'-GAFa-Rluc, and cAMP did not appear to activate the sensor, although it was only tested up to $1 \mu \mathrm{M}$ in lysates [28]. This finding is intriguing as it raises the possibility that this truncation of PDE5 may be more optimal than the one described by Nikolaev et al. [19], which was incorporated into CYGYEL. However, two caveats must be noted. First, GFP2_-GAFa-Rluc may act as a "sink" that sequesters cGMP in the cell, suggesting that cGMP may have a slow off-rate and remains bound, preventing its degradation by PDEs, thus making it difficult to detect the kinetics of signalling [28]. Second, our own results have demonstrated that CYGYEL is dynamic and reversible, able to detect the kinetics of cGMP activity over extended periods of time; yet similar kinetic assays were not conducted using GFP²-GAFaRluc [28]. This may be in part related to the use of the BRET ${ }^{2}$ methodology, which does not typically allow extended time courses due to weak emissions and a rapid loss of signal [30]. In contrast, $\mathrm{BRET}^{1}$ maintains a high luminescence for a longer duration and allows for a higher throughput. Due to these factors, we cannot directly compare the activity of the two biosensors and are unsure of the temporal resolution of GFP2 - GAFa-Rluc. Future studies could convert $\mathrm{GFP}^{2}$-GAFa-Rluc to BRET ${ }^{1}$ in order to directly compare the temporal resolution and reversibility of the two different truncations of PDE5, in order to determine the utility of each truncation as a sensor domain.

Similarly, future studies could also aim to increase the affinity of cGMP for CYGYEL or other cGMP biosensors while at the same time decreasing the affinity of cAMP, with the caveat that very high affinities might lead to sequestration cGMP [28]. Interestingly, a variant of cGES-DE5 that swapped the ECFP/EYFP FRET pair to a T-sapphire/dimer2 FRET pair showed substantial increases in both affinity for cGMP $(\sim 40 \mathrm{nM})$ and selectivity for cGMP over cAMP [31], allowing the detection of cGMP in adult cardiomyocytes [32]. However, as we have shown, changing the ECFP/EYFP pair to Rluc8/Venus did not have the same effect on selectivity. Additionally, the recently developed FRET-based cGMP sensor PfPKG, which was based on PKG (rather than PDE5) from Plasmodium falciparum, showed a high cGMP affinity of about $23 \mathrm{nM}$, but this was coupled with a high cAMP affinity of about $4.6 \mu \mathrm{M}$, suggesting that it may be difficult to decouple the affinities of the two cyclic nucleotides for cGMP-binding domains [33]. In fact, the authors even mutated the cGMP-binding domain from PKG in an attempt to reduce the affinity of cAMP, but were unsuccessful [33].

The compartmentalisation of cyclic nucleotides is a current research topic in cell biology [34], and although cGMP compartmentalisation is less well understood than that of cAMP, it does appear that there are spatially segregated pools of cGMP within the cell $[35,36]$, which is not surprising given that sGC and pGC are already separately localised. 
Importantly, microdomains of cGMP may have different functional roles in cardiovascular physiology, which is still under investigation [37]. The ability of a biosensor to detect cGMP, and its selectivity for cGMP over cAMP, may differ depending on whether lysates or live cells are stimulated, and may also differ based on cell type, due to the differential expression and compartmentalisation of enzymes that regulate cyclic nucleotide levels within the cell. Notably, CYGYEL showed diffuse cytoplasmic expression when cells expressing CYGYEL were imaged using a fluorescence microscope, which was consistent with its ability to detect cGMP synthesised by either sGC or pGC in live cells. Although BRET is not typically used to detect localised signalling, it may be possible to do this by targeting the biosensor to particular locations of interest, such as the membrane [38]. Alternatively, cGES-DE5 may be used as a complementary biosensor to detect localised signalling via sGC versus pGC in single cells, for example, which is one of the primary advantages of FRET over BRET. Additionally, the recent development of enhanced Nano-lanterns [39] enabled the generation of a dual FRET/BRET-based cAMP biosensor [40], and it would be interesting to see whether a similar approach is viable for the generation of a single cGMP sensor that can be used for plate-based assays in addition to cellular microscopy.

In summary, we have generated a genetically encoded, BRET-based biosensor for cGMP activity that streamlines the process of detecting cGMP compared to traditional end point assays. CYGYEL can detect changes in sGC- and pGC-mediated cGMP activity over time in the plate-based format, and the lentiviral vector allows for the generation of human cell lines stably expressing the biosensor, allowing the detection of cGMP across physiologically relevant cell types.

\section{Methods}

\subsection{Materials and Reagents}

1H-[1,2,4] Oxadiazolo[4,3-a]quinoxaline-1-one (ODQ), 3-isobutyl-1-methylxanthine (IBMX), adenosine $3^{\prime}, 5^{\prime}$-cyclic monophosphate sodium salt monohydrate, C-type natriuretic peptide (CNP), diethylamine NONOate diethylammonium salt (DEA), forskolin, guanosine $3^{\prime}, 5^{\prime}$-cyclic monophosphate sodium salt, Polybrene, Tris base, and vardenafil, were from Sigma-Aldrich (Burlington, MA, USA). Dulbecco's modified Eagle medium (DMEM), Medium 199 (M199), L-glutamine, and penicillin-streptomycin (P/S) were from Gibco (Waltham, MA, USA). Foetal bovine serum (FBS) was from Scientifix (Melbourne, VIC, Australia). EGM-2 endothelial cell growth medium-2 BulletKit was from Lonza (Basel, Switzerland). Smooth muscle cell growth supplement was from ScienCell (Carlsbad, CA, USA). Ethylenediaminetetraacetic acid disodium salt dihydrate (EDTA) was from ChemSupply (Adelaide, SA, Australia). Coelenterazine $h$ was from Nanolight (Pinetop, AZ, USA).

\subsection{Design of a BRET-Based Biosensor for cGMP Activity}

The BRET-based biosensor CYGYEL was created based on the cGES-DE5 FRET-based biosensor [19]. cGES-DE5 consists of the cGMP-binding domain (Glu154 to Ala308) from human PDE5A1 (GenBank accession number NM_001083) inserted between enhanced yellow fluorescent protein (EYFP) and enhanced cyan fluorescent protein (ECFP) using the EcoRI and XbaI restriction sites, respectively. The sequence for EYFP was replaced with the sequence for Venus, and the sequence for ECFP was replaced with the sequence for Rluc8. A Kozak sequence (GCCACC) was placed before the start codon, and the gene for the biosensor was synthesised by GenScript (Piscataway, NJ, USA) into pcDNA3.1/Zeo ${ }^{(+)}$ between the NheI and ApaI restriction sites.

\subsection{Cell Culture}

All cells were cultured at $37^{\circ} \mathrm{C}$ with $5 \% \mathrm{CO}_{2}$. HEK293T cells (CRL-3216) were cultured in DMEM supplemented with 10\% FBS, $1 \%$ L-glutamine, and 1\% P/S. Human umbilical vein smooth muscle cells (HUVSMCs) were grown in M199 supplemented with 5\% heatinactivated FBS, $1 \% \mathrm{P} / \mathrm{S}$, and smooth muscle cell growth supplement. Human umbilical 
vein endothelial cells (HUVECs) were grown in EGM-2 endothelial cell growth medium2 (including $2 \%$ FBS) supplemented with $1 \% \mathrm{P} / \mathrm{S}$. These are henceforth referred to as "complete media". HUVSMCs were purchased from ScienCell.

\subsection{Isolation of Human Umbilical Vein Endothelial Cells}

This study was approved by the Monash Health Human Research and Ethics Committee (HREC: 01067B). Healthy term umbilical cord from singleton pregnancies were collected, with informed written consent, at the time of elective caesarean section. Exclusion criteria included multiple pregnancy, maternal medical conditions, any history of preeclampsia and/or foetal growth restriction, smoking, alcohol or drug use during pregnancy. Exclusions were made for the following medications: antihypertensive, aspirin, nonsteroidal anti-inflammatory drugs, or thyroid medications. To isolate HUVECs, the

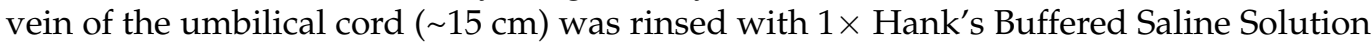
(HBSS) until all blood was removed. Luer-lok fittings were placed at both ends of the vein and $10 \mathrm{~mL}$ of collagenase type II $(0.5 \mathrm{mg} / \mathrm{mL}$ in HBSS $)$ syringed into the vein. The cord was then incubated for $10 \mathrm{~min}$ at $37{ }^{\circ} \mathrm{C}$ in a humidified $95 \%$ air $/ 5 \% \mathrm{CO}_{2}$ incubator. The collagenase was collected by a syringe and placed in a $50 \mathrm{~mL}$ falcon tube. The vein was washed twice with $10 \mathrm{~mL} \mathrm{EBM}^{\mathrm{TM}}-2$ endothelial cell growth media (Lonza), which was collected and added into the falcon tube. The tube was spun at $500 \times g$ for 5 min at room temperature to pellet the cells. Cells were resuspended in $5 \mathrm{~mL} \mathrm{EBM}^{\mathrm{TM}}-2$ media and cultured in a T25 flask at $37{ }^{\circ} \mathrm{C}$ in a humidified incubator at $95 \%$ air $/ 5 \% \mathrm{CO}_{2}$. Cells were passaged to P2 before slowly freezing in 90\% FBS and 10\% DMSO (1 million cells $/ \mathrm{mL}$ ) and stored in liquid nitrogen.

\subsection{Cloning CYGYEL into a Lentiviral Vector}

CYGYEL was cloned into a lentiviral vector under the control of the constitutive human Ef1 $\alpha$ promoter using Gateway technology (Invitrogen), according to the manufacturer's instructions. The CYGYEL coding sequence from the pcDNA3.1/ $\mathrm{Zeo}^{(+)}$vector was flanked with appropriate $a t t \mathrm{~B} 5$ and $a t t \mathrm{~B} 2$ sequences and amplified by polymerase chain reaction (PCR) using the forward primer $5^{\prime}$ GGGG ACA ACT TTG TAT ACA AAA GTT GGC CAC CAT GGT GAG CAA GGG C $3^{\prime}$ and reverse primer 5' GGGG ACC ACT TTG TAC AAG AAA GCT GGG TAT TA CTG CTC GTT CTT CAG CAC 3'. The PCR product of the correct size was extracted, gel-purified, and cloned into the pDONR 221 P5-P2 vector using BP Clonase II. The resulting pENTR L5-L2 entry clone was confirmed to have the correct sequence using Sanger sequencing. Our pENTR L1-R5 Ef1 $\alpha$ entry clone was cloned along with the pENTR L5-L2 CYGYEL clone into the pLenti X1 Zeo DEST vector [41] using LR Clonase II, to generate the pLenti X1 Ef1 $\alpha$ CYGYEL expression clone.

\subsection{Generation of HEK-CAMYEL and HEK-CYGYEL Cell Lines via Lentiviral Transduction}

HEK293T stably expressing the cAMP sensor CAMYEL [25] or CYGYEL were generated using crude lentivirus. HEK293T cells were plated at 3.5 million cells on a $10 \mathrm{~cm}$ dish. The next day, cells were transfected with $8 \mu \mathrm{g}$ of either pLenti X1 Ef1 $\alpha$ CAMYEL [42] or pLenti X1 Ef1 $\alpha$ CYGYEL, along with the lentiviral packaging and envelope plasmids pMDL, pRSV-Rev, and pCMV-VSV-G, using Lipofectamine 2000. The following day, HEK293T cells to be transduced were plated on a $10 \mathrm{~cm}$ dish at 400,000 cells. The next day, media containing lentivirus from transfected cells were harvested and filtered through a $0.45 \mu \mathrm{m}$ syringe filter. The newly plated HEK293T cells were transduced by replacing the cell culture media with the media containing lentivirus, mixed with $4 \mu \mathrm{g} / \mathrm{mL}$ hexadimethrine bromide (Polybrene) to increase transduction efficiency. Three rounds of transduction were performed over $32 \mathrm{~h}$, before allowing cells to recover for three days in complete DMEM.

\subsection{Purification of Lentivirus and Transduction of Primary Vascular Cells}

CYGYEL lentivirus was produced in HEK293T cells and purified for transduction of primary cells. HEK293T cells were plated out on five $20 \mathrm{~cm}$ dishes at 11 million cells per 
dish. The next day, cells were transfected with the pLenti X1 Ef1 $\alpha$ CYGYEL expression clone, pMDL/pRRE, pRSV-Rev, and pCMV-VSV-G, using Lipofectamine 2000. Two days later, media containing secreted lentivirus was harvested and spun at $2000 \mathrm{rpm}$ for five minutes to pellet any cellular debris. The supernatant was then filtered through a $0.45 \mu \mathrm{m}$ filter and spun in a Hitachi CP100MX ultracentrifuge at approximately $72,000 \times g$ at $4{ }^{\circ} \mathrm{C}$ for two and a half hours to pellet the virus. The supernatant was then discarded, and $50 \mu \mathrm{L}$ of cold phosphate-buffered saline (PBS) was added per tube (for a total of $150 \mu \mathrm{L}$ per viral preparation), which was stored at $4{ }^{\circ} \mathrm{C}$ overnight. Some of the crude lentivirus-containing media were also stored at $4{ }^{\circ} \mathrm{C}$ overnight. The next day, the virus was resuspended in the PBS, pooled, then stored in aliquots at $-80^{\circ} \mathrm{C}$. Moreover, $1 \mu \mathrm{L}$ of the virus was also used for a visual titration on HEK293T cells, along with some of the crude lentivirus, to ensure that it was of high enough titre to transduce cells in vitro.

HUVECs and HUVSMCs were transduced with the purified virus in a T175 flask at approximately $70 \%$ confluency. Then, $5 \mu \mathrm{L}$ of purified lentivirus was resuspended in cell culture media along with $4 \mu \mathrm{g} / \mathrm{mL}$ hexadimethrine bromide (Polybrene). Cell culture media in the flask were replaced with virus-containing media, which were left on cells overnight before replacing it with fresh cell culture media.

\subsection{Flow Cytometry and Fluorescence-Activated Cell Sorting}

Transduced cells were sorted from non-transduced cells using fluorescence-activated cell sorting (FACS), using a Becton Dickinson FACSAria III. Cells were isolated by gating after plotting the forward scatter area (FSC-A) against the side scatter area. Single cells were isolated after plotting the side scatter height against the side scatter width and the forward scatter height (FSC-H) against the forward scatter width. Dead cells stained with DAPI were removed after laser excitation at $405 \mathrm{~nm}$ and gating FSC-A against emissions at $450 / 40 \mathrm{~nm}$. From the population of single, live cells, cells showing higher YFP emissions than control cells, as detected after laser excitation at $488 \mathrm{~nm}$ and emissions at 530/30 nm, were sorted into separate populations, as noted. Cells were subsequently grown to confluency in a T175 flask and cryopreserved. For HUVECs, the cells were already expressing "high" levels of a relaxin family peptide receptor 1 (RXFP1)-internal ribosome entry site (IRES)-green fluorescent protein (GFP) construct, from a previous transduction and sort (Figure S1); however, emissions were separated from YFP emissions by using separate emission filters for GFP $(510 / 20 \mathrm{~nm})$ and YFP $(530 / 30 \mathrm{~nm})$ and applying compensation. These cells had subsequently been cryopreserved. For analytical flow cytometry, cells were isolated as above, but with the following exceptions: a Beckman Coulter CytoFLEX S was used, single cells were isolated after plotting only for FSC-A versus FSC-H, and YFP was detected using a 525/40 nm emission filter.

\subsection{Fluorescence Microscopy}

HEK293T cells that were stably expressing "high" levels of CYGYEL were imaged using a Leica DM IL LED microscope with DFC450 C camera, EL6000 external light source, and GFP filter, at $20 \times$ magnification.

\subsection{BRET Assays in Live Cells}

HEK293T cells, HUVSMCs, or HUVECs stably expressing either CYGYEL or CAMYEL were seeded onto 96-well CulturPlate microplates (PerkinElmer, Waltham, MA, USA) and were incubated overnight. At the time of the assay, HEK293T or HUVSMC cell culture media were replaced with phenol red free complete media containing $25 \mathrm{mM}$ HEPES and $5 \mu \mathrm{M}$ coelenterazine $h$, whereas HUVEC cell culture media, EGM-2, were replaced with complete EGM- 2 containing $25 \mathrm{mM}$ HEPES and $5 \mu \mathrm{M}$ coelenterazine $h$. Emissions were detected simultaneously from Rluc (CAMYEL) or Rluc8 (CYGYEL) $(475 / 30 \mathrm{~nm}$ ) and citrine (CAMYEL) or Venus (CYGYEL) $(525 / 30 \mathrm{~nm})$ using a PHERAstar FSX plate reader (BMG Labtech, Ortenberg, Germany) at $37^{\circ} \mathrm{C}$. Emissions were read for five minutes to establish a baseline before addition of a vehicle or ligand. 


\subsection{BRET Assays in Cell Lysates}

HEK-CYGYEL cells were washed and resuspended in DPBS, and then centrifuged in order to pellet the cells. DPBS was aspirated and cells were resuspended in buffer containing $5 \mathrm{mM}$ Tris and $2 \mathrm{mM}$ EDTA ( $\mathrm{pH} 7.3$ ), then sonicated on low power for three $10 \mathrm{~s}$ cycles at $4{ }^{\circ} \mathrm{C}$. Lysates were then spun down at $21,000 \times g$ for $20 \mathrm{~min}$ at $4{ }^{\circ} \mathrm{C}$, after which the supernatant was obtained and stored at $-80^{\circ} \mathrm{C}$ or used for BRET assays. During the assay, lysates were mixed with coelenterazine $h(5 \mu \mathrm{M})$, distributed into a white, 384-well OptiPlate (PerkinElmer) with lysates corresponding to the equivalent of approximately 5000 cells per well, and then assayed as above using a PHERAstar FSX plate reader. Cell lysates were also used to generate spectral scans, using a CLARIOstar plate reader (BMG Labtech).

\subsection{Presentation of BRET Data}

The ligand-induced BRET ratio was calculated by subtracting the ratio of acceptor channel emissions $(525 / 30 \mathrm{~nm})$ to donor channel emissions $(475 / 30 \mathrm{~nm})$ for vehicle wells from the same ratio for treated wells:

ligand-induced BRET ratio

$$
=\frac{\text { acceptor channel (ligand) }}{\text { donor channel (ligand) }}-\frac{\text { acceptor channel (vehicle) }}{\text { donor channel (vehicle) }}
$$

For time courses, the ligand-induced BRET ratio was plotted against time, with the last prereading before ligand addition displayed as the zero time point (time of vehicle/ligand addition). For CAMYEL cAMP data only, decreases in ligand-induced BRET ratio represent increases in cAMP, so all values were subtracted from zero. For spectral scan data, the wavelength $(\mathrm{nm})$ was plotted against emissions. Concentration-response curves were fit to the data by applying three-parameter nonlinear regressions to the area under the curve data, using Prism 9 from GraphPad (San Diego, CA, USA).

Supplementary Materials: The following supporting information can be downloaded at: https: //www.mdpi.com/article/10.3390/ijms23031908/s1.

Author Contributions: Conceptualization, A.L.V., M.K. and R.A.D.B.; methodology, A.L.V., M.K., D.J.S. and R.A.D.B.; investigation and analysis, A.L.V. and M.K.; resources, D.J.S., S.M. and R.A.D.B.; writing—original draft preparation, A.L.V. and R.A.D.B.; writing—review and editing, A.L.V., B.H., D.J.S. and R.A.D.B.; supervision, M.K. and R.A.D.B.; funding acquisition, D.J.S. and R.A.D.B. All authors have read and agreed to the published version of the manuscript.

Funding: This research was supported by National Health and Medical Research Council of Australia project grants (1100676) and (2001027) (R.A.D.B.) and the Victorian Government Operational Infrastructure Support Program. R.A.D.B. is supported by an NHMRC Research Fellowship (1042650). A.L.V. was supported by an Australian Government Research Training Program PhD Scholarship.

Institutional Review Board Statement: This study was approved by the Monash Health Human Research and Ethics Committee (HREC: 01067B).

Data Availability Statement: Not applicable.

Acknowledgments: The authors thank Tania Ferraro and Sharon Layfield for technical assistance; and V. Jameson and J. Kie (MBC Flow Cytometry Facility) for assistance with FACS.

Conflicts of Interest: The authors declare that they have no conflict of interest with the contents of this article.

\section{References}

1. Feil, R.; Hofmann, F.; Kleppisch, T. Function of cGMP-dependent Protein Kinases in the Nervous System. Rev. Neurosci. 2005, 16, 23-42. [CrossRef]

2. Hofmann, F.; Biel, M.; Feil, R.; Kleppisch, T. Mouse Models of NO/Natriuretic Peptide/cGMP Kinase Signaling; Springer: Berlin/Heidelberg, Germany, 2004; pp. 95-130. [CrossRef]

3. Tsai, E.J.; Kass, D.A. Cyclic GMP signaling in cardiovascular pathophysiology and therapeutics. Pharmacol. Ther. 2009, 122, 216-238. [CrossRef] 
4. Derbyshire, E.R.; Marletta, M.A. Structure and Regulation of Soluble Guanylate Cyclase. Annu. Rev. Biochem. 2012, 81, 533-559. [CrossRef]

5. Kuhn, M. Molecular Physiology of Membrane Guanylyl Cyclase Receptors. Physiol. Rev. 2016, 96, 751-804. [CrossRef]

6. Francis, S.H.; Busch, J.L.; Corbin, J.D. cGMP-Dependent Protein Kinases and cGMP Phosphodiesterases in Nitric Oxide and cGMP Action. Pharmacol. Rev. 2010, 62, 525-563. [CrossRef]

7. Miller, M.R.; Megson, I.L. Recent developments in nitric oxide donor drugs. J. Cereb. Blood Flow Metab. 2007, 151, 305-321. [CrossRef]

8. Conole, D.; Scott, L.J. Riociguat: First Global Approval. Drugs 2013, 73, 1967-1975. [CrossRef]

9. Lasker, G.F.; Pankey, E.A.; Kadowitz, P.J. Modulation of Soluble Guanylate Cyclase for the Treatment of Erectile Dysfunction. Physiology 2013, 28, 262-269. [CrossRef]

10. A Waldman, S.; Camilleri, M. Guanylate cyclase-C as a therapeutic target in gastrointestinal disorders. Gut 2018, 67, 1543-1552. [CrossRef]

11. Buglioni, A.; Burnett, J.C. New Pharmacological Strategies to Increase cGMP. Annu. Rev. Med. 2016, 67, 229-243. [CrossRef]

12. Shim, S.; Shuman, M.; Duncan, E. An emerging role of cGMP in the treatment of schizophrenia: A review. Schizophr. Res. 2016, 170, 226-231. [CrossRef]

13. Lukowski, R.; Krieg, T.; Rybalkin, S.D.; Beavo, J.; Hofmann, F. Turning on cGMP-dependent pathways to treat cardiac dysfunctions: Boom, bust, and beyond. Trends Pharmacol. Sci. 2014, 35, 404-413. [CrossRef]

14. Windham, P.F.; Tinsley, H.N. cGMP signaling as a target for the prevention and treatment of breast cancer. Semin. Cancer Biol. 2015, 31, 106-110. [CrossRef]

15. Aissa, M.; Lee, S.; Bennett, B.; Thatcher, G. Targeting NO/cGMP Signaling in the CNS for Neurodegeneration and Alzheimer's Disease. Curr. Med. Chem. 2016, 23, 2770-2788. [CrossRef]

16. Greene, S.J.; Gheorghiade, M.; Borlaug, B.A.; Pieske, B.; Vaduganathan, M.; Burnett, J.C.; Roessig, L.; Stasch, J.; Solomon, S.D.; Paulus, W.J.; et al. The cGMP Signaling Pathway as a Therapeutic Target in Heart Failure With Preserved Ejection Fraction. J. Am. Hear. Assoc. 2013, 2, e000536. [CrossRef]

17. Herenbrink, C.K.; Sykes, D.; Donthamsetti, P.; Canals, M.; Coudrat, T.; Shonberg, J.; Scammells, P.; Capuano, B.; Sexton, P.M.; Charlton, S.; et al. The role of kinetic context in apparent biased agonism at GPCRs. Nat. Commun. 2016, 7, 10842. [CrossRef]

18. Honda, A.; Adams, S.R.; Sawyer, C.L.; Lev-Ram, V.; Tsien, R.Y.; Dostmann, W.R.G. Spatiotemporal dynamics of guanosine $3^{\prime}, 5^{\prime}$-cyclic monophosphate revealed by a genetically encoded, fluorescent indicator. Proc. Natl. Acad. Sci. USA 2001, 98, 2437-2442. [CrossRef]

19. Nikolaev, V.; Gambaryan, S.; Lohse, M.J. Fluorescent sensors for rapid monitoring of intracellular cGMP. Nat. Chem. Biol. 2005, 3, 23-25. [CrossRef]

20. Sato, M.; Hida, N.; Ozawa, T.; Umezawa, Y. Fluorescent Indicators for Cyclic GMP Based on Cyclic GMP-Dependent Protein Kinase I $\alpha$ and Green Fluorescent Proteins. Anal. Chem. 2000, 72, 5918-5924. [CrossRef]

21. Clegg, R.M. Förster resonance energy transfer-FRET what is it, why do it, and how it's done. In Laboratory Techniques in Biochemistry and Molecular Biology, 1st ed.; Gadella, T.W.J., Ed.; Academic Press: Burlington, ON, Canada, 2008; Volume 33, pp. 1-57.

22. Boute, N.; Jockers, R.; Issad, T. The use of resonance energy transfer in high-throughput screening: BRET versus FRET. Trends Pharmacol. Sci. 2002, 23, 351-354. [CrossRef]

23. Russwurm, M.; Mullershausen, F.; Friebe, A.; Jäger, R.; Russwurm, C.; Koesling, D. Design of fluorescence resonance energy transfer (FRET)-based cGMP indicators: A systematic approach. Biochem. J. 2007, 407, 69-77. [CrossRef] [PubMed]

24. Ramamurthi, A.; Lewis, R.S. Measurement and Modeling of Nitric Oxide Release Rates for Nitric Oxide Donors. Chem. Res. Toxicol. 1997, 10, 408-413. [CrossRef] [PubMed]

25. Jiang, L.I.; Collins, J.; Davis, R.; Lin, K.-M.; DeCamp, D.; Roach, T.; Hsueh, R.; Rebres, R.A.; Ross, E.M.; Taussig, R.; et al. Use of a CAMP BRET Sensor to Characterize a Novel Regulation of cAMP by the Sphingosine 1-Phosphate/G13 Pathway. J. Biol. Chem. 2007, 282, 10576-10584. [CrossRef]

26. Rivero-Vilches, F.J.; De Frutos, S.; Saura, M.; Rodriguez-Puyol, D.; Rodriguez-Puyol, M. Differential relaxing responses to particulate or soluble guanylyl cyclase activation on endothelial cells: A mechanism dependent on PKG-I $\alpha$ activation by NO/cGMP. Am. J. Physiol. Physiol. 2003, 285, C891-C898. [CrossRef] [PubMed]

27. Chen, H.; Levine, Y.C.; Golan, D.E.; Michel, T.; Lin, A.J. Atrial Natriuretic Peptide-initiated cGMP Pathways Regulate Vasodilatorstimulated Phosphoprotein Phosphorylation and Angiogenesis in Vascular Endothelium. J. Biol. Chem. 2008, 283, $4439-4447$. [CrossRef] [PubMed]

28. Biswas, K.H.; Sopory, S.; Visweswariah, S.S. The GAF Domain of the cGMP-Binding, cGMP-Specific Phosphodiesterase (PDE5) Is a Sensor and a Sink for cGMP. Biochemistry 2008, 47, 3534-3543. [CrossRef]

29. Bertrand, L.; Parent, S.; Caron, M.; Legault, M.; Joly, E.; Angers, S.; Bouvier, M.; Brown, M.; Houle, B.; Ménard, L. The BRET2/arrestin assay in stable recombinant cells: A platform to screen for compounds that interact with $\mathrm{G}$ protein-coupled receptors (GPCRS). J. Recept. Signal Transduct. Res. 2002, 22, 533-541. [CrossRef]

30. Hamdan, F.F.; Audet, M.; Garneau, P.; Pelletier, J.; Bouvier, M. High-Throughput Screening of G Protein-Coupled Receptor Antagonists Using a Bioluminescence Resonance Energy Transfer 1-Based $\beta$-Arrestin2 Recruitment Assay. J. Biomol. Screen. 2005, 10, 463-475. [CrossRef] 
31. Niino, Y.; Hotta, K.; Oka, K. Simultaneous Live Cell Imaging Using Dual FRET Sensors with a Single Excitation Light. PLoS ONE 2009, 4, e6036. [CrossRef]

32. Götz, K.R.; Sprenger, J.U.; Perera, R.K.; Steinbrecher, J.H.; Lehnart, S.E.; Kuhn, M.; Gorelik, J.; Balligand, J.-L.; Nikolaev, V.O. Transgenic Mice for Real-Time Visualization of cGMP in Intact Adult Cardiomyocytes. Circ. Res. 2014, 114, 1235-1245. [CrossRef] [PubMed]

33. Calamera, G.; Li, D.; Ulsund, A.H.; Kim, J.J.; Neely, O.C.; Moltzau, L.R.; Bjørnerem, M.; Paterson, D.; Kim, C.; Levy, F.O.; et al. FRET-based cyclic GMP biosensors measure low cGMP concentrations in cardiomyocytes and neurons. Commun. Biol. 2019, 2, 394. [CrossRef] [PubMed]

34. McCormick, K.; Baillie, G.S. Compartmentalisation of second messenger signalling pathways. Curr. Opin. Genet. Dev. 2014, $27,20-25$. [CrossRef] [PubMed]

35. Castro, L.R.V.; Verde, I.; Cooper, D.M.; Fischmeister, R. Cyclic Guanosine Monophosphate Compartmentation in Rat Cardiac Myocytes. Circulation 2006, 113, 2221-2228. [CrossRef]

36. Piggott, L.A.; Hassell, K.A.; Berkova, Z.; Morris, A.P.; Silberbach, M.; Rich, T.C. Natriuretic Peptides and Nitric Oxide Stimulate cGMP Synthesis in Different Cellular Compartments. J. Gen. Physiol. 2006, 128, 3-14. [CrossRef]

37. Bork, N.I.; E Molina, C.; Nikolaev, V.O. cGMP signalling in cardiomyocyte microdomains. Biochem. Soc. Trans. 2019, 47, 1327-1339. [CrossRef]

38. Matthiesen, K.; Nielsen, J. Cyclic AMP Control Measured in Two Compartments in HEK293 Cells: Phosphodiesterase KM Is More Important than Phosphodiesterase Localization. PLoS ONE 2011, 6, e24392. [CrossRef]

39. Suzuki, K.; Kimura, T.; Shinoda, H.; Bai, G.; Daniels, M.J.; Arai, Y.; Nakano, M.; Nagai, T. Five colour variants of bright luminescent protein for real-time multicolour bioimaging. Nat. Commun. 2016, 7, 13718. [CrossRef]

40. French, A.R.; Tesmer, A.L.; Tantama, M. Dual-Mode FRET and BRET Sensors for Detecting cAMP Dynamics. ACS Omega 2019, 4, 15504-15511. [CrossRef]

41. Campeau, E.; Ruhl, V.E.; Rodier, F.; Smith, C.L.; Rahmberg, B.L.; Fuss, J.O.; Campisi, J.; Yaswen, P.; Cooper, P.K.; Kaufman, P.D. A Versatile Viral System for Expression and Depletion of Proteins in Mammalian Cells. PLoS ONE 2009, 4, e6529. [CrossRef]

42. Valkovic, A.L.; Leckey, M.B.; Whitehead, A.; Hossain, M.A.; Inoue, A.; Kocan, M.; Bathgate, R.A.D. Real-time examination of cAMP activity at relaxin family peptide receptors using a BRET-based biosensor. Pharmacol. Res. Perspect. 2018, 6, e00432. [CrossRef] [PubMed] 